FRBSF Working Paper 2002-21

\title{
United States Disability Policy in a Changing Environment
}

\author{
Richard V. Burkhauser \\ Cornell University \\ Department of Policy Analysis and Management \\ N134 Martha Van Rensselaer Hall \\ Ithaca, NY 14853 \\ (607) 255-2097 \\ rvb1@cornell.edu \\ Mary C. Daly \\ Economic Research Department \\ Federal Reserve Bank of San Francisco \\ 101 Market Street, Mail Stop 1130 \\ San Francisco, CA 94105 \\ (415) 974-3186 \\ mary.daly@sf.frb.org
}

September 2001

We thank Carol D'Souza and Jaqueline Yuen for research support and Martha Bonney and Anita Todd for editorial assistance. None of these individuals are responsible for any errors. This research is funded in part by the United States Department of Education, National Institute on Disability and Rehabilitation Research, cooperative agreement No. 13313980038. It does not necessarily reflect the view of the National Institute on Disability and Rehabilitation Research, the Federal Reserve Bank of San Francisco, or the Federal Reserve System. 


\section{Introduction}

The Americans with Disabilities Act of 1990 extended civil rights protection against discrimination in employment to people with disabilities. The passage of the ADA represented an explicit effort to change the focus of United States disability policy away from incometransfers for people with disabilities who remained out of the labor market toward employment support for people with disabilities who faced disability-related workplace hurdles that prevented employment. The argument underlying this shift in focus was that by removing disabilityrelated barriers to employment, individuals with disabilities would be allowed greater freedom to choose work over disability benefit receipt. Despite these efforts, the greatest impact of federal government policy on people with disabilities continues to be felt through two income-transfer programs: Social Security Disability Insurance (DI) and Supplemental Security Income (SSI). ${ }^{1}$ Moreover, circumstantial evidence suggests that the passage of the ADA may not have improved the employment opportunities of people with disabilities. During the 1990s, the employment rate among working-age people with disabilities fell and disability benefit rolls and expenditures grew. ${ }^{2}$

Here we provide a broader perspective from which to evaluate current disability policy. We begin by reviewing the major aspects of the DI and SSI programs. We then examine trends in employment and disability benefit receipt among those with disabilities, paying particular

${ }^{1} \mathrm{DI}$ is a social insurance program targeted on regularly employed workers who experience a disability that completely prevents them from working. SSI is a means-tested categorical welfare program that provides minimum cash benefit to those whose disability completely prevents them from working. Other disability transfer programs such as Workers' Compensation and Veterans Disability Benefits also provide income support but are targeted only to those whose disability occurred at work and provide protection to partially and temporarily disabled workers.

${ }^{2}$ The trend towards rising caseloads and expenditures began in the mid-1980s. However, the pace of growth increased during the 1990s. 
attention to the last 15 years. Within this framework we summarize the primary difficulties in crafting an efficient and equitable assistance program for a heterogeneous population that changes with its environment. Finally, we place disability policy in the context of the broader United States social welfare system and consider how changes in other social welfare programs likely will affect disability program usage in the future.

\section{Overview of United States Disability Policy}

Disability policy in the United States combines two basic components: transfers and employment protection. ${ }^{3}$ Federal disability transfers-Social Security Disability Insurance (DI) and Supplemental Security Income (SSI) — are limited to the subset of individuals with disabilities who are unable to perform any substantial gainful activity. Employment protection, provided through the Americans with Disabilities Act of 1990 (ADA), covers a much broader group of individuals with disabilities, including those who are able to work in the labor market.

\section{DI and SSI}

The origins of DI and SSI can be traced to the Social Security Act of $1935 .^{4}$ Both programs are administered by the Social Security Administration and use the same strict definition of eligibility: "the inability to engage in substantial gainful activity, by reason of a medically determinable physical or mental impairment that is expected to result in death or last at least 12 months" (Social Security Administration, 2000). ${ }^{5}$ Applicants must be unable to do

\footnotetext{
${ }^{3}$ Rehabilitation, job training, and work programs are a third but much smaller component of disability policy at the federal level. See Aarts, Burkhauser, and DeJong (1998) for a discussion of workrelated programs in a cross-national context.

${ }^{4}$ DI was created under Title II and SSI under Title XVI of the Social Security Act.

${ }^{5}$ The United States does not award federal disability benefits for partial or temporary disability but only for permanent and total disability.
} 
any work that exists in the national economy for which they are qualified by virtue of age, education, and work experience. In addition, there is a five-month waiting period before permanent benefits begin. A person applies for DI or SSI benefits at an office of the Social Security Administration (SSA). Once the federal officials and the applicant have gathered sufficient information to complete the application, it is submitted to a state agency for determination of disability. Disability examiners in this office, working with the aid of vocational and medical consultants, act as the primary gatekeepers of both the DI and SSI programs. Although the criteria for determining eligibility for disability benefits is set at the federal level and is uniform across states, the results of the determination process can and do vary greatly from state to state. ${ }^{6}$

While DI and SSI are administered by the Social Security Administration (SSA) and share a common health-based disability eligibility criteria, the goals of the programs and remaining eligibility criteria are quite different. DI is part of the Old-Age, Survivor, and Disability Insurance (OASDI) program. The goal of DI is to provide "earnings replacement insurance" for those who exit the labor force because of disability. DI benefits are financed through a payroll tax (0.90\% in 2000), paid by both employees and employers. Taxes are levied on earnings up to an annual maximum — $\$ 76,200$ of earnings in 2000 - that is updated each year in relation to increases in national average annual earnings. To qualify for DI benefits, an individual must have worked in employment subject to Social Security contributions for about one-fourth of the time elapsing after age 21 and up to the year of disability. In addition, he or

\footnotetext{
${ }^{6}$ Burkhauser, Butler, and Weathers (forthcoming) show that mean allowance rates (initial acceptances to initial applications) between 1974 and 1993 varied considerably across states, ranging from lows of 28 in Louisiana and New Mexico to highs of 48 in Delaware, New Jersey, and Rhode Island.
} 
she must have recent covered work-equivalent to five of the preceding ten years (or, if between ages 24 and 31, half the time since age 21, or if under age 24, half of the preceding three years). Benefits are paid based on past earnings using a formula that provides lower earners with higher replacement rates. ${ }^{7}$ Since DI is an insurance program, benefits are not means-tested. ${ }^{8}$

In contrast, SSI is a means-tested transfer program aimed at the aged, and blind and disabled adults and children. The target population for the adult disability program is workingage men and women whose disabilities are as severe as those required under DI, but who have too little work experience to qualify for DI benefits or whose combined DI benefits and other sources of household income fall below the maximum allowable to receive SSI benefits. To be eligible for SSI, an individual's countable income must be less than the federal benefit rate (FBR) — \$512 per month (\$6,144 per year) in 2000 — and countable resources must be less than $\$ 2,000$. For jointly eligible couples the income and resource limits were $\$ 9,288$ and $\$ 3,000$, respectively. ${ }^{9}$ In 2000 , the maximum monthly federal SSI benefit was $\$ 512$ (\$769 for a jointly eligible couple).

The DI and SSI programs serve very different populations. Bound, Burkhauser, and Nichols (2001) use information on applicants to both programs to find that the average DI applicant is more likely to be older, male, white, non-Hispanic, married, have at least a highschool degree, live in a smaller household, and have more financial wealth than the average SSI recipient. The pre-application household income of DI applicants is more than twice that of SSI

\footnotetext{
${ }^{7}$ For more detailed information regarding eligibility requirements and benefit formulas for DI, see Social Security Administration (2000).

${ }^{8}$ See Bound and Burkhauser (1999) for a detailed discussion of the DI program.

${ }^{9}$ See Daly and Burkhauser (forthcoming) for a detailed discussion of the SSI program.
} 
applicants and is very close to that of non-applicants for DI. In terms of the income-to-need ratio (using the U.S. Census poverty thresholds), the pre-application ratio among DI applicants is more than twice that of SSI applicants and is almost exactly that of non-applicants for DI.

Finally, the vast majority of those who applied for DI benefits were employed 36 months prior to initial application, while the vast majority of SSI applicants were not employed 36 months prior to initial application.

In 2000, about 7.7 million individuals, 5.3 percent of the working-age population, received federal disability payments. Within this group, 50 percent received DI, 37 percent received SSI, and 13 percent received benefits from both programs.

\section{Basic Elements of the ADA}

The definition of disability under the ADA is far broader than the one used to determine disability benefit receipt. The ADA defines disability as a physical or mental impairment that substantially limits one or more major life activity, a record of such an impairment, or being regarded as having such an impairment. Title I of the ADA requires employers to make reasonable accommodations to workers with disabilities unless it would cause undue hardship on the operation of business. As of July 26, 1992, all employers with 25 or more workers were subject to its rules. Two years later the requirement was extended to all employers with 15 or more workers. ${ }^{10}$

\section{Trends in Employment Rates and Disability Benefit Caseloads}

As measured by self-reported work limitations, the prevalence of disability among all working-age individuals has changed little over the past two decades, averaging about 8 percent

\footnotetext{
${ }^{10}$ Who is actually protected by the ADA with respect to a right to sue is an unsettled issue in the law. Recent Supreme Court rulings have narrowed eligibility. See Berkeley Journal of Employment and Labor Law (2000) for a fuller discussion.
} 
between 1981 and 2000 (Burkhauser, Daly, Houtenville, and Nargis, 2001). This consistency of disability prevalence over time holds across age, gender, race, and household income decile.

Over the same period, employment rates and DI and SSI caseloads have varied greatly, fluctuating with the economy, changes in benefit eligibility criteria, and the implementation of other public policies intended to support people with disabilities. ${ }^{11}$

Figure 1 summarizes the primary relationships dominating research on United States disability policy. The figure shows employment rates of working-age men and women with selfreported work limitations (based on the Current Population Survey) and the number of individuals receiving disability benefits (based on data from the SSA) for the period 19801999. ${ }^{12}$ Also indicated in the figure are the 1984 disability screening liberalization, the passage of the ADA, and periods of recession in the 1980s and 1990s (shaded bars).

The trends in Figure 1 highlight the major concerns of disability policymakers regarding the success of federal initiatives to protect and support people with disabilities. As the figure shows, the number of beneficiaries of disability transfers increased following eligibility expansion and liberalization in 1984. While benefit rolls increased slowly over the rest of the decade, employment rates also rose through the business cycle expansion of the late 1980s. It was not until the start of the 1990s, following additional easing of DI and SSI benefit eligibility, the passage of the ADA, and a marked slowdown in the national economy, that benefit rolls rose rapidly and employment rates fell. These trends did not reverse during the 1990s expansion.

For some analysts, these outcomes reflect increasing benefit support for workers with

${ }^{11}$ See Bound and Burkhauser, 1999 and Rupp and Stapleton, 1998 for detailed reviews of changes in disability benefit eligibility criteria over the past several decades.

${ }^{12}$ Employment rates are taken from Burkhauser, Daly, and Houtenville (2001). Data on DI and SSI beneficiaries come from the Social Security Administration (2000). 
disabilities who have limited labor market opportunities. For others, they reflect the usual moral hazard problems and work disincentive effects that accompany liberalizations of eligibility criteria in social programs. For still others, lower employment rates and rising benefit rolls are evidence of the unintended consequences of the employer accommodation mandate in the ADA. ${ }^{13}$ Although there is no consensus on what produced these trends, the outcome is clear; at the end of the 1990s, despite seven straight years of substantial economic growth, a smaller fraction of working-age individuals with disabilities worked and a larger fraction relied on federal disability income transfers than ever before.

\section{Hurdles to Crafting Effective Disability Policy}

\section{Finding a Consistent Policy Goal}

The passage of the ADA challenged the conventional policy wisdom that working-age people with disabilities could not and hence should not be expected to work. Proponents of the ADA argued that unequal access to jobs—rather than a worker's impairment—was the primary barrier to employment. In the extreme, there is no such thing as a disabled worker, only a society that does not fully accommodate its citizens. If all citizens were fully accommodated, the disability-transfer population would be zero. This argument raises a basic question with respect to the rights and responsibilities of people with disabilities. Most fundamentally, should people with disabilities categorically be expected to work?

\footnotetext{
${ }^{13} \mathrm{~A}$ number of papers have examined the causality behind the trends displayed in Figure 1.
} DeLiere (2000) and Acemoglu and Angrist (forthcoming) blame the ADA for the downturn in employment among those with disabilities. Bound and Waidman (2001) argue that changes in disability benefit programs allowed workers to leave the labor force and take benefits. Autor and Duggan (2001) suggest that increasing replacement rates of disability benefits and declining job opportunities for lowskilled workers induced workers to choose benefits over employment. 
A positive answer to this question shifts the boundaries of the population expected to work in our society. On the one hand, it suggests that non-productivity resulting from discrimination with regard to access to work should be stopped. On the other hand, it suggests that eligibility criteria for permanent earnings replacement (DI) or for a categorical guaranteed income floor (SSI) based on disability should be reevaluated. As opportunities for employment and the marketplace productivity of people with disabilities increases, the lines drawn between those with disabilities and other groups who experience disproportionate difficulties finding work-low-skilled or less-educated younger persons or single mothers facing welfare limits—are blurring.

\section{Defining and Capturing the Target Population}

Disability is a more complex concept to define or measure than age, race, or gender. It is a dynamic process rather than a static classification. It varies with both the health of the individual and the socioeconomic environment in which the person functions, confounding attempts to measure it objectively and consistently. The work response to the onset of health conditions depends not only on the severity of the impairment, but also on the social environment —including the availability of employment, the availability of accommodation, rehabilitation and retraining, the presence of legal supports or protections, and the accessibility and generosity of DI, SSI, and other government transfer programs.

Operationalizing a definition or definitions of disability for policy purposes is even more difficult. ${ }^{14}$ Figure 2 illustrates the relationship between the definitions described earlier for the ADA and DI and SSI programs. Circle A contains the working-age population with disabilities

\footnotetext{
${ }^{14}$ Mashaw and Reno (1996) document over 20 definitions of disability used for purposes of entitlement to public and private transfers, government services, or statistical analysis.
} 
as defined by the ADA. Circle $\mathrm{B}$ is the working-age population that is eligible for disability transfers, based solely on health impairments, although some of the members work and hence do not meet the work test for DI or SSI. Circle C contains the working-age population with disabilities who actually receive disability benefits. Circles B and C are subsets of circle A but do not coincide for several reasons. Some people in circle B, who would be eligible for benefits if they stopped working, keep working, and some are denied benefits even though they are not working. Hence, some people in circle B are not in circle C. Likewise, some people in circle C are awarded benefits even though they are not "truly" eligible.

\section{Limiting Behavioral Responses to Policy Rules}

Like all public policy-based programs, disability programs must contend with potential moral hazard problems and with work disincentives induced by program rules. ${ }^{15}$ The magnitude of these problems depends in large part on whether adults with disabilities are able or expected to work, and on the precision of disability screening. If people with disabilities are unable or not expected to work, then marginal tax rates on benefits could approach 100 percent with no change in work behavior. DI and SSI could provide relatively high replacement rates or income guarantees and still maintain relatively low break-even points (the income level at which a person is no longer eligible for benefits). Moreover, if work disability is a clearly defined and immutable category, differences in replacement rates, guarantees, time-limits, or funding mechanisms for disability and other programs would have little effect on allowances and caseloads. Participation in disability benefit programs would be purely a function of the prevalence of health limitations in the working-age population. Our experience with DI and SSI

\footnotetext{
${ }^{15}$ See Bound and Burkhauser (1999), Daly and Burkhauser (forthcoming), and Hoynes and Moffitt (1996) for a review of these issues as they pertain to DI and SSI.
} 
suggests that this does not describe the real world. As with other social insurance and welfare programs, the disability benefit system, together with economic conditions, clearly affects work behavior.

Hence, while circle A in Figure 2 is determined by health-based impairments, the size and location of circles B and C are determined by social policies and how people with disabilities, employers, and frontline program administrators react to them. Judgments by administrative gatekeepers, economic conditions, accommodation, and the $\mathrm{X}$-factor that makes people more or less willing to work all influence the share of the population with disabilities in each circle.

\section{Balancing Efficiency and Equity Concerns}

Disability policymakers historically have tried to maintain a balance between efficiency and equity. This means that the optimal level of support is not necessarily one that has no behavioral impact on benefit applications, work, or savings. Even if actual disability status were perfectly observable, society would still want to target some level of benefits on disadvantaged low-income workers and their families even if it resulted in some efficiency losses. Moreover, in a world where the socially appropriate eligibility standard for DI and SSI is difficult to assess, some individuals will be denied benefits who are less capable of work than is socially acceptable. Moving to a more lenient eligibility criteria involves a trade-off between reducing the risk of a denial of benefits to those who "deserve" them and the additional costs of awarding benefits to those who do not "deserve" them. For policymakers the issue is: in the presence of uncertainty, do the social benefits of lenient eligibility criteria outweigh the efficiency costs of 
providing these funds to some who are more capable of work. ${ }^{16}$

\section{Disability Policy and the Broader Social Welfare System}

As Figure 3 illustrates, disability programs are only one part of a social welfare system that attempts to ameliorate the consequences of a separation from the labor market over a worker's lifetime for economic as well as health reasons. These programs can influence the response of both employers and workers, when such a separation is imminent. For workers who remain on the job over their work life the path to retirement is straightforward. Not until they reach early retirement age do they have to choose between retirement and continued work. But for a significant number of workers, job separation before retirement is a reality that social welfare policy must anticipate.

To put Figure 3 in focus, it is useful to recognize that the typical working-age person with a disability in the United States was able-bodied during most of his or her lifetime. For instance Burkhauser and Daly (1996), using data from the Health and Retirement Study, find that, in 1992, 70 percent of men and women aged 51 to 61 who reported having a health-related impairment said it started during their work life. Thus, social welfare policy may influence not only whether such workers remain in the labor force or end up in a transfer program, but also the speed at which such transitions take place. Figure 3 illustrates the importance of social welfare policies by considering four paths that workers may take following the onset of a health-related impairment.

The work path encompasses public programs that provide or encourage rehabilitation to overcome the work limitations caused by a disability. It also includes more direct labor market

\footnotetext{
${ }^{16}$ See Bound, Cullen, Nichols, and Schmidt (2001) for a detailed discussion of these issues.
} 
intervention through the creation of specific government jobs for people with disabilities, subsidies to those who employ such workers, job quotas, and job protection legislation—dismissal rules or general antidiscrimination legislation requiring accommodation for workers with disabilities. The ADA clearly falls into this category. Work path policies attempt to maintain those with disabilities on the job and in the labor market, either through the carrot of subsidies or the stick of mandates.

The disability insurance path encompasses traditional disability insurance-based transfer programs. These include short-term sickness programs, which mandate employers to replace lost wages during the first few weeks of sickness or directly provide such replacement through short-term social insurance. In the United States health care and short-term sickness benefits are provided through private contracts between employers and employees with only limited government regulation over the terms and conditions of those contracts. After some point, workers are then eligible to move to a long-term disability insurance program, which often has both health and employment criteria. This path eventually merges with the Social Security Disability Insurance program. For those with disabilities who drop out of the labor force, the disability insurance path is the most common public program path.

The unemployment path encompasses short-term unemployment benefits to replace lost wage earnings due to cyclical economic downturns. At some point longer-term unemployment insurance becomes available, often at a lower replacement rate. Eventually, this also merges with the Social Security retirement system. Disentangling job exits because of a health condition from job exits due to economic forces is in practice a difficult and often controversial task, especially as these exits are influenced by the rules established by the social welfare system.

The welfare path encompasses means-tested programs that serve as a safety net for 
workers without jobs who are not eligible for health- or unemployment-based social insurance. Welfare programs can be universal, subject only to a means test and/or linked to an inability to work either because of poor health, poor job skills, or child-rearing responsibilities. This track continues past retirement age for those few individuals who are not eligible for Social Security retirement benefits.

When a health condition begins to affect the ability to work, important job-related decisions must be made by workers and their employers. Workers will consider the relative rewards of continued movement along the work path versus entry onto an alternative path. In like manner, employers' willingness to accommodate their workers will also be influenced by the social policies within which the firm must operate.

This is not to suggest that all workers can or will transform themselves into candidates for disability transfer programs. Rather, it recognizes that those with work limitations who are having difficulty with their current job or who are no longer working will be influenced by the relative rewards provided by the disability insurance, unemployment, and welfare paths in deciding whether to remain in the labor force or to apply for transfer benefits. Disability transfer applicants will increase as relative replacement rates rise, the period over which benefits can be received lengthens, and the probability of acceptance onto the rolls grows.

Although DI and SSI are income transfer programs narrowly targeted on those with disabilities, the fluidity of boundaries defining who is and who is not eligible implies that policy changes in other programs such as unemployment insurance, retirement benefits, and welfare likely will also affect DI and SSI caseloads. Thus, if limits are placed on other programs such as welfare and unemployment insurance, the number of those receiving disability benefits will be relatively large. 


\section{Putting Disability Policy on the Agenda}

Two factors are likely to cause the debate surrounding disability policy to intensify over the next decade. First, the protracted period of economic growth that the United States has experienced since 1992 cannot last forever. And, as was shown in Figure 1, applications for DI and SSI are sensitive to the business cycle. A downturn in the economy will increase applications and heighten efforts to broaden the categorical definition of disability. This is even more likely since the welfare reforms of 1996 have made it more difficult for low-income people to be eligible for other programs. Second, the percentage of the population aged 50 and over is increasing. Given that the prevalence of disability rises sharply at these ages, applications for both DI and SSI are likely to rise. The effect of this demographic change is magnified by the fact that in 2000 the age of eligibility for full Social Security retirement benefits began to rise from 65 to 67 . This increase in the normal retirement age will increase the relative value of DI and SSI benefits for workers considering exiting the labor market prior to age 67. All these factors suggest another major round of debate over disability policy and program expansion is in the near future. 


\section{References}

Aarts, L., R.V. Burkhauser, and P.R. de Jong. 1996. Curing the Dutch Disease: an International Perspective on Disability Policy Reform. Aldershot, UK: Avebury.

Acemoglu, D. and J. Angrist. Forthcoming. "Consequences of Employment Protection? The Case of the Americans with Disabilities Act" Journal of Political Economy.

Autor, D. and M. Duggan. 2001. "The Rise in Disability and the Decline in Unemployment." Mimeo, Department of Economics. Cambridge, MA: Massachusetts Institute of Technology.

Berkeley Journal of Employment and Labor Law. 2000. Special Issue on Backlash Against the ADA: Interdisciplinary Perspectives and Implications for Social Justice Strategies. Volume 21, Number 1. 2000.

Bound, J. and R.V. Burkhauser. 1999. "Economic Analysis of Transfer Programs Targeted on People with Disabilities." in Handbook of Labor Economics, Volume 3(c), edited by O. Ashenfelter and D. Card. Amsterdam: Elsevier Science: 3417-3528.

Bound, J., R.V. Burkhauser, A. Nichols. 2001. "Tracking the Household Income of SSDI and SSI Applicants." Michigan Retirement Research Consortium Working Paper.

Bound, J., J.B. Cullen, A. Nichols, and L. Schmidt. 2001. "The Welfare Implications of Increasing DI Benefit Generosity.” Michigan Retirement Research Consortium Working Paper. Ann Arbor, MI: University of Michigan.

Bound, J. and T. Waidman. 2001. "Accounting for Recent Declines in Employment Rates Among the Working-Aged Disabled." NBER Working Paper 7975. Cambridge, MA: National Bureau of Economic Research.

Burkhauser, R.V. and M.C. Daly. 1996b. "Employment and Economic Well-Being Following the Onset of a Disability: The Role for Public Policy.” In Jerry Mashaw, Virginia Reno, Richard V. Burkhauser, and Monroe Berkowitz (eds.), Disability, Work, and Cash Benefits. Kalamazoo, MI: W.E. Upjohn Institute for Employment Research, pp. 59-102.

Burkhauser, Richard V. and Mary C. Daly. 1996a. "The Potential Impact on the Employment of People with Disabilities." In Jane West (ed.), Implementing The Americans with Disabilities Act. Cambridge, MA: Blackwell Publishers, pp. 153-192.

Burkhauser, R.V., M.C. Daly, and A. Houtenville. 2001. "How Working Age People with Disabilities Fared over the 1990s Business Cycle.” In P. Budetti, R. Burkhauser, J. Gregory, and A. Hunt (eds.), Ensuring Health and Income Security for an Aging Workforce. Kalamazoo, MI: W.E. Upjohn Institute for Employment Research. 
Burkhauser, R.V., M.C. Daly, A. Houtenville, and N. Nargis. 2001. "Economic Outcomes of Working-Age People with Disabilities over the Business Cycle: An Examination of the 1980s and 1990s." Working Paper, 2001-07. San Francisco, CA: Federal Reserve Bank.

Daly, M.C. and R.V. Burkhauser. Forthcoming. "The Supplemental Security Income Program," in Means-Tested Programs in the United States. Chicago and Cambridge: University of Chicago Press and NBER.

DeLeire, Thomas. 2000. "The Wage and Employment Effects of the Americans with Disabilities Act." Journal of Human Resources 35(4): 693-715.

Hoynes, H. and R. Moffitt. 1996. “The Effectiveness of Financial Work Incentives in Social Security Disability Insurance and Supplemental Security Income: Lessons from Other Transfer Programs." In J. Mashaw et. al. Disability, Work and Cash Benefits. Kalamazoo, MI. W.E. Upjohn Institute for Employment Research.

Lewin-VHI. 1999. "Policy Evaluation of the Overall Effects of Welfare Reform on SSA Programs." Final Report and Appendix. Washington, DC: The Office of the Assistant Secretary for Planning and Evaluation, U.S. Department of Health and Human Services and the Social Security Administration

Mashaw, Jerry and Virginia Reno. 1996. Balancing Security and Opportunity: the Challenge of Disability Income Policy. Report of the Disability Policy Panel, National Academy of Social Insurance, Washington, DC.

Rupp, K. and C. Scott. 1998. "Determinants of Duration on the Disability Rolls and Program Trends." In Kalman Rupp and David Stapleton (eds.) Growth in Disability Benefits: Explanations and Policy Implications. Kalamazoo, MI W.E. Upjohn Institute for Employment Research, 139-176.

Rupp, K. and D. Stapleton. 1995. "Determinants of the Growth in the Social Security Administration's Disability Programs: An Overview." Social Security Bulletin 58(4): 4370.

Social Security Administration. 2000. Annual Statistical Supplements to the Social Security Bulletin, 1975-2000. Washington, DC: U.S. General Printing Office. 
Figure 1.

Disability Benefit Rolls and Employment Rates among

Recipients Working-Age Men and Women with Disabilities

Employment Rate (\%)

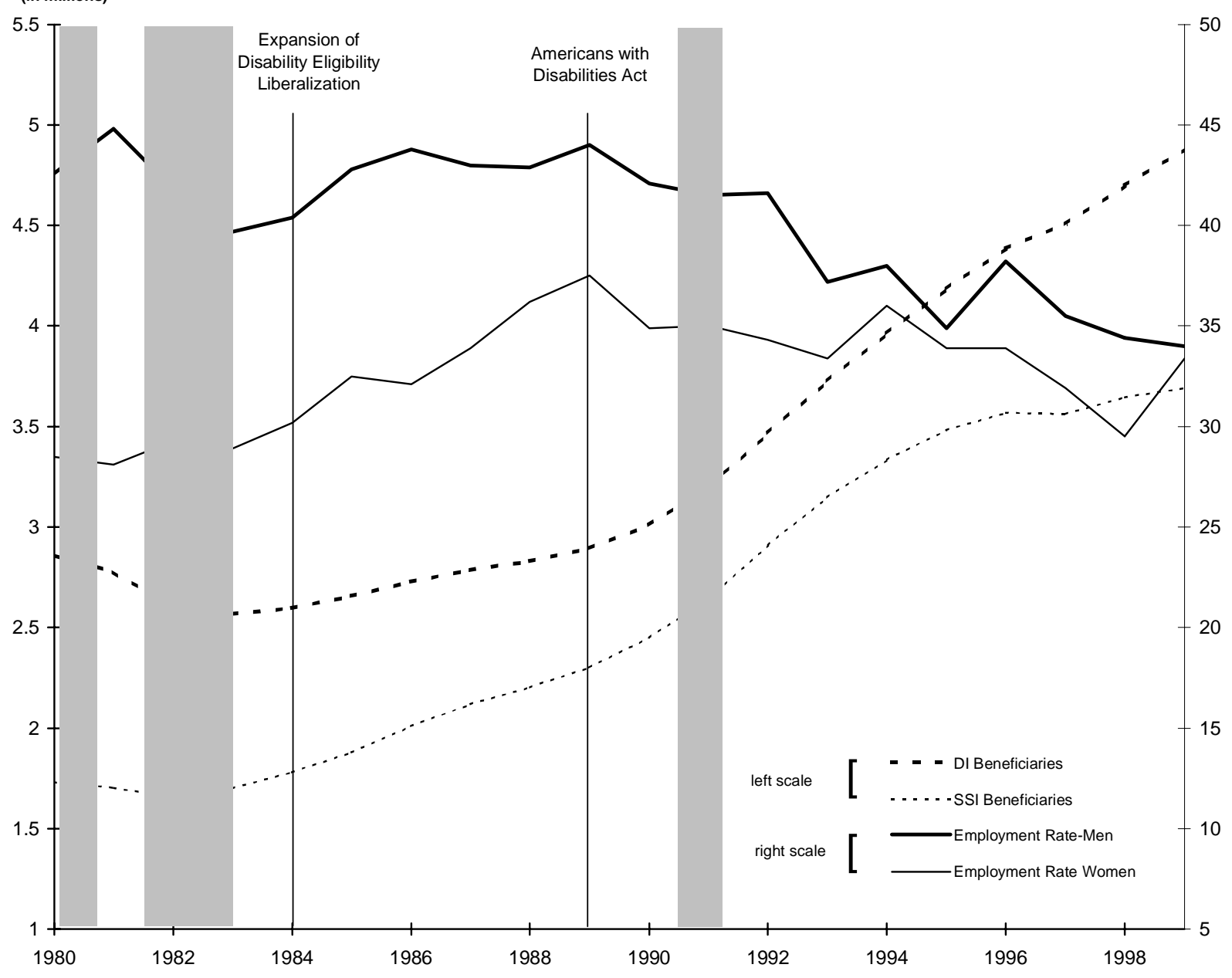


Figure 2

Defining the Population with Disabilities

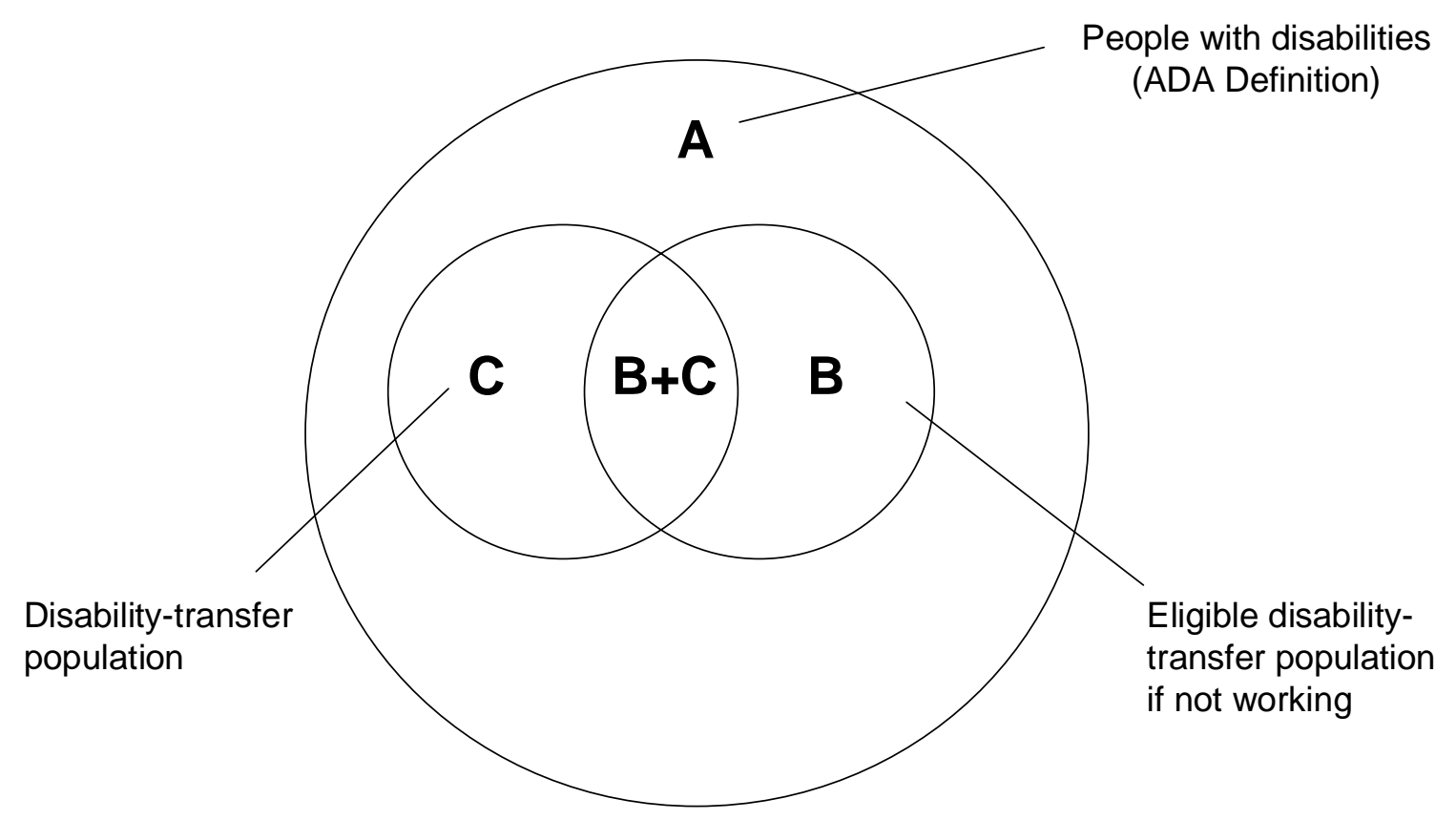


Figure 3: Alternative life paths following the onset of a disability

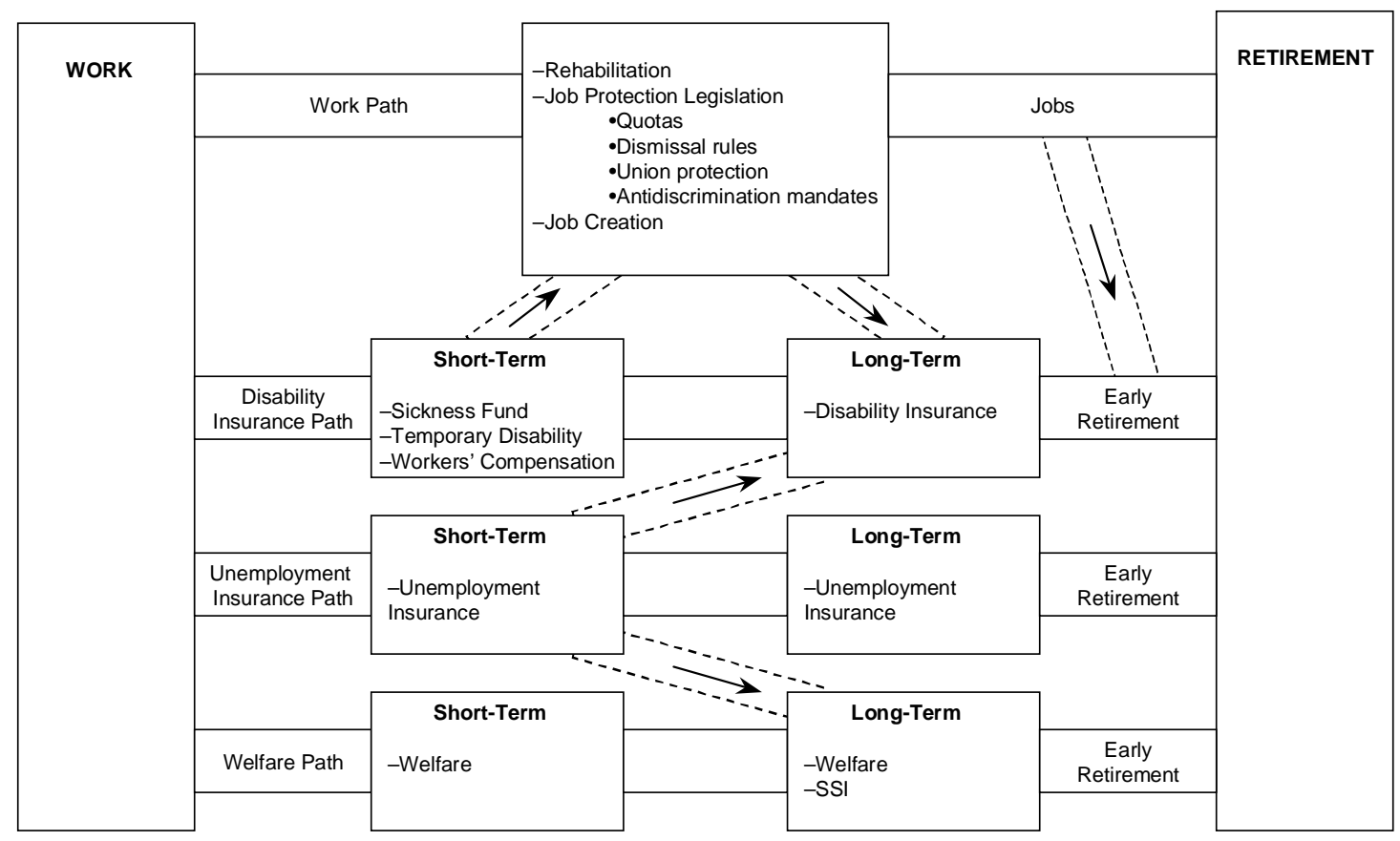

$-19$ 